\title{
Correspondence
}

Contents: Brain, mind, and behaviour/Life events and relapse in bipolar disorder/Is there a lithium withdrawal syndrome?/Ethnic nomenclature/Morbidity among social phobics/Perinatal psychiatry: East is East and West is West/An attachment school of psychotherapy/Tricyclic-induced seizures and absent ECT response/Cannabis toxic psychosis while on disulfiram/Pain and seasonal affective disorder/The rarity of mania in Down's syndrome.

\section{Brain, mind, and behaviour}

SIR: Dr Fenwick (BJP, November 1993, 163, 565573) argues cogently for the use of up-to-date neuropsychiatric techniques in the diagnosis of offenders referred for medical reports. This is a valid and important message which forensic psychiatry is just beginning to grapple with, and we will clearly need increasing sophistication in our investigation of offenders and more access to techniques such as imaging.

There is, however, a false implication running through the lecture which should not be allowed to cloud the important issues concerning diagnosis. The implication is that matters of responsibility are matters for the psychiatrist. I understand how easy it is for an assumption of this kind to arise, because, burdened with difficult decisions, lawyers, including judges, will, on occasion, attempt to share with psychiatrists, or even unload on to them, matters of this kind. The position is however quite straightforward. Questions of responsibility, culpability, and imputability (including mitigation) are matters for courts, lawyers, and juries. They are moral and philosophical matters. They have nothing to do with science or medicine. They are emotional constructions developed by human society, in every part of the world, in order to grade and justify punishment.

Doctors had no part in this process until the 19th century. As knowledge advanced, those who have to make these difficult moral judgements have increasingly asked for scientific information before doing so. The doctor's role in court therefore is to present the data concerning diagnosis, structural damage, psychological damage, or other problems suffered by the individual being examined, and discuss, if asked, the possible influence of these identified features on the individual's behaviour. By this means it is hoped that the ultimate questions about responsibility and mitigation will be better informed. Those ultimate decisions will, however, necessarily be taken by those who make the moral judgements. Therefore while commending Dr Fenwick's article to psychiatric colleagues, especially trainees, I would like to emphasise to them that they should not take from his article a message that somehow or other it will be appropriate for them to usurp these non-medical moral matters.

I might add that in my view we, as psychiatrists, should look to our own moral issues concerning the provision of better diagnosis and, above all, better treatment. Having gone through all sorts of philosophical deliberations, courts are faced with the difficulty that whatever they think about the morality or otherwise of an individual, if they want that individual to have some medical treatment they are dependent on psychiatrists to provide it. We should respond as readily as we can to such requests for medical care.

\section{Institute of Psychiatry \\ Denmark Hill}

London SE5 8AF

SIR: I cannot pass without comment Dr Fenwick's suggestions that for the medical expert witness giving evidence in court there is a conflict between "brain words" and "mind words" and that "brain words" are more precise than "mind words". Not so: brains and minds are quite different things. The language that is appropriate for speaking about minds is not appropriate for speaking about brains, and vice versa. It makes no more sense to speak of a "guilty brain" than it does to speak of a "hypoxic mind", or indeed of an "angry car". To do so is to commit a category mistake (Ryle, 1949). Such expressions cut across the logic of our language: they are nonsense. Nor can one translate from "mind words" to "brain words", because they refer to different phenomena. One cannot, for example, report a computerised tomography scan in "mind words". For the same reason it is not true to say that "brain words" are more precise than "mind words", or the reverse.

The language that we use for talking about mental phenomena is extensive and complex, and includes many subtle distinctions, but nonetheless most people manage to use it correctly most of the time 